\title{
ANÁLISE DE OPORTUNIDADES DE DESENVOLVIMENTO DE CONSCIÊNCIA DE ABERTURA DE VOGAIS ORAIS DO PORTUGUÊS BRASILEIRO EM CINCO MANUAIS DE PORTUGUÊS LÍNGUA ESTRANGEIRA
}

\author{
Daiane dos Santos Ferreira (FURG) \\ Luciana Pilatti Telles (FURG)
}

\begin{abstract}
RESUMO: Este artigo tem por objetivo investigar as oportunidades de desenvolvimento de consciência fonológica das vogais médias-baixas do português $/ \varepsilon / \mathrm{e} / \mathrm{J} / \mathrm{em}$ cinco materiais didáticos voltados ao ensino do português brasileiro para aprendizes estrangeiros. Para a realização desta pesquisa, foram consultados os seguintes materiais didáticos: Brasil Intercultural 1 e 2; Brasil Intercultural 3 e 4; Novo Avenida Brasil 1; Diálogo Brasil Curso Intensivo de Português para Estrangeiros e Passagens - Português do Brasil para estrangeiros. Buscamos avaliar, nos materiais analisados, as oportunidades de desenvolvimento de habilidades de consciência fonológica, como reconhecimento e manipulação (ALVES, 2012). Para a análise das vogais, recorremos aos pressupostos teóricos da Fonologia Autossegmental (CLEMENTS; HUME, 1995). Ao analisar os materiais didáticos, verificamos que os exercícios propostos nos cinco livros selecionados são, basicamente, de discriminação auditiva, de classificação e de pronúncia em repetição e que não oportunizam o desenvolvimento de consciência de abertura das vogais orais do português brasileiro, uma vez que não estimulam a percepção de regularidades do sistema fonológico e a manipulação de seus constituintes. Propomos, após a análise, atividades para o nível A1.
\end{abstract}

PALAVRAS-CHAVE: Consciência Fonológica em Português Língua Adicional/ Estrangeira (PLA/PLE). Vogais médias-baixas do português brasileiro. Análise de materiais didáticos.

\begin{abstract}
This paper investigates opportunities for phonological awareness development in BrazilianPortuguese low-mid vowels $/ \varepsilon /$ and / $/$ / addressed in four textbooks used for the teaching of the language to foreign students. Four book series provided guidance for this research: Brasil Intercultural 1 e 2; Brasil Intercultural $3 e$ 4; Avenida Brasil 1; Diálogo Brasil e Passagens - Português do Brasil para estrangeiros. In the teaching textbooks, we sought to analyze the opportunities for the development of phonological awareness abilities as recognition, and sound recognition and manipulation (ALVES, 2012). In order to analyze the vowels, we searched for the theoretical background in Autosegmental Phonology (CLEMENTS; HUME, 1995). Our analysis of the teaching textbooks revealed that the listening, associating classifying and repeating activities proposed by Brasil Intercultural 1 e 2; Brasil Intercultural 3 e 4; Avenida Brasil 1; Diálogo Brasil e Passagens- Português do Brasil para estrangeiros do not allow the awareness development concerning the opening of oralvowels in Brazilian Portuguese, since they do not stimulate the perception of regularities in the phonological system and the sound recognition and manipulation of its components. Besides the analysis, we propose activities for A1 level.
\end{abstract}

KEYWORDS: Phonological Awareness in Brazilian Portuguese as Foreign Language. Low-mid vowels in Brazilian Portuguese. Textbooks analysis.

\section{INTRODUÇÃO}

A língua portuguesa tem assumido atualmente um grande status no cenário mundial, com a busca, por pessoas de diversas partes do mundo, para aprender esse idioma. Isso parece ocorrer em decorrência dos acordos firmados pelo Brasil com diversos países, e o aumento do 


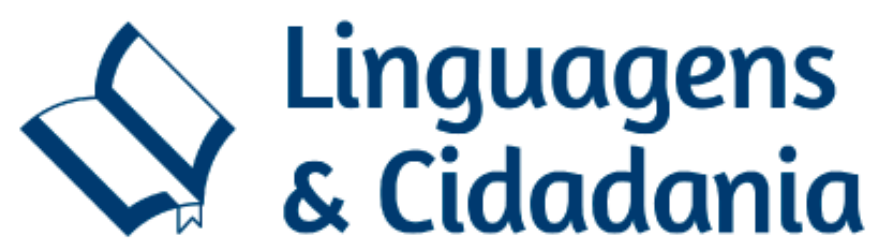

número de pessoas interessadas pela aprendizagem do idioma faz com que o português como língua estrangeira adquira importância crescente (OLIVEIRA, 2013; ANÇÃ, 2015).

Na perspectiva de difusão e promoção na área de português língua adicional/ estrangeira (PLA/PLE), além de instituições brasileiras de ensino superior que desenvolvem projetos de pesquisa, ensino e extensão, há também a atuação da difusão da cultura e da língua portuguesa em suas variedades brasileiras nos Centros Culturais Brasileiros e nos Institutos Culturais Bilaterais, através da atuação de professores leitores e da avaliação de proficiência em português brasileiro pelo exame Celpe-Bras (Certificado de Proficiência em Língua Portuguesa para Estrangeiros), com abrangência dentro e fora do país.

Ainda referente à consolidação da língua portuguesa no âmbito nacional e internacional, em 2014, ela, assim como outras línguas estrangeiras, passou a compor o catálogo de cursos do Programa Idiomas sem Fronteiras (IsF) ${ }^{1}$. O Programa tornou-se uma importante iniciativa para auxiliar no processo de internacionalização e para o desenvolvimento de políticas linguísticas nas universidades brasileiras, dentre as quais a Universidade Federal do Rio Grande (FURG).

Na FURG, além das ações do IsF, há a certificação de proficiência em leitura de textos em línguas estrangeiras e a oferta de cursos sequenciais do Centro de Línguas Estrangeiras (CELE). O Curso de Português como Língua Estrangeira, vinculado ao CELE, é um projeto de extensão destinado a alunos de diversos cursos de graduação e pós-graduação da Universidade. A questão de pesquisa apresentada neste artigo surgiu das experiências de uma das autoras como ministrante em uma turma do curso de extensão, em atendimento a estudantes oriundos da Colômbia, do Peru, do México e do Uruguai.

Por meio dessas experiências, foi possível observar a dificuldade dos discentes quanto à percepção e à produção de vogais médias-baixas do português brasileiro. Conforme apontam diversos estudos, a aquisição das vogais médias do português brasileiro por falantes de espanhol estabelece dificuldades, tanto em termos de percepção quanto de produção (ALLEGRO, 2014; MACHRY DA SILVA, 2015).

Constatando essa dificuldade dos estudantes hispano-falantes do curso de PLE na extensão da FURG quanto à percepção e à produção de vogais orais médias-baixas, ressaltamos a importância do desenvolvimento de consciência de abertura das vogais orais do português

1Instituído pela Portaria n. 973, de 14 de novembro de 2014.

Linguagens \& Cidadania, v. 20, n. esp., jan./dez. 2018. 


\section{W. Linguagens}

brasileiro. Logo, diante da identificação dessa dificuldade, buscamos fazer um levantamento das oportunidades para o ensino das vogais médias-baixas do português presentes em materiais didáticos de PLA/PLE já existentes no mercado.

Para o desenvolvimento da análise, é preciso entender que o conhecimento da gramática sonora da língua pode ser implícito, pelo contato com a língua, ou explícito, pelo desenvolvimento de consciência fonológica, a qual consiste na habilidade que o falante/aprendiz desenvolve para reconhecer e manipular constituintes fonológicos, como frases e palavras fonológicas, rimas, sílabas e segmentos (LOPES, 2004; ALVES, 2012).

Através da experiência com os alunos hispano-falantes, surgiram-nos dois questionamentos: (1) Os materiais escolhidos para análise, se tomados como único ponto de referência, instrumentalizam professores e alunos acerca das vogais médias-baixas do português brasileiro? (2) Os manuais de PLE apresentam atividades que oportunizam o desenvolvimento de consciência fonológica acerca das vogais médias-baixas do português brasileiro?

Diante do exposto acima, com este estudo, pretendemos atingir os objetivos relacionados abaixo.

(1) Objetivo geral: Investigar as oportunidades de desenvolvimento de consciência fonológica das vogais médias-baixas do português em cinco materiais didáticos voltados ao ensino do português brasileiro para aprendizes estrangeiros.

(2) Objetivos específicos: (a) averiguar e discutir a disponibilidade, nos materiais didáticos de PLE, de conteúdos que viabilizem o desenvolvimento de conhecimento da(s) gramática(s) fonológica(s) do português falado no Brasil; (b) analisar as oportunidades de desenvolvimento de consciência fonológica no que se refere às vogais médias das variedades do português falado no Brasil em posição tônica; (c) verificar de que maneira os livros didáticos de PLE abordam as vogais médias-baixas; (d) avaliar as propostas dos materiais didáticos a partir da noção de consciência fonológica; (e) contribuir para o desenvolvimento de materiais de PLA/PLE, apresentando propostas de atividades de consciência fonológica de abertura das vogais médias.

Este artigo está estruturado da seguinte forma: na introdução, discorremos sobre o contexto da língua portuguesa como língua estrangeira, sobre algumas políticas governamentais e instituições que oferecem cursos de PLA/PLE; na segunda seção, descrevemos as vogais nas 


\section{Q Linguagens}

línguas românicas e apresentamos, como referencial teórico, noções de consciência fonológica e, como representação, os modelos não lineares. Na seção da metodologia, descrevemos a forma como coletamos os dados para análise, apresentando os manuais considerados e seus exercícios em seções destinadas à Fonética e à Fonologia. Temos, na sequência, a análise dos materiais, as propostas de atividades de consciência fonológica da abertura das vogais orais do português, e, por fim, encaminhamos as nossas considerações finais.

\section{AS VOGAIS NO PORTUGUÊS E NO ESPANHOL, GEOMETRIA DE TRAÇOS E REGRAS}

O português e o espanhol são línguas próximas por sua origem a partir de uma mesma família linguística e pelas semelhanças morfossintáticas que guardam entre si (ALMEIDA FILHO, 2001). Apesar disso, com o passar do tempo, foram mudando e se distanciando em alguns aspectos de sua estrutura, como por exemplo, no que se refere ao componente fonológico. Neste trabalho, nos debruçamos sobre as diferenças entre o sistema vocálico do português brasileiro (PB) e do espanhol.

O sistema vocálico do PB é constituído por sete vogais orais (/a, e, $\varepsilon, \mathrm{i}, \mathrm{o}, \supset, \mathrm{u} /$ ), as quais podem variar de acordo com o acento e a posição na palavra. Apesar de o espanhol ser considerado uma língua próxima ao português por ter origem latina, o sistema vocálico espanhol apresenta somente cinco vogais (/a, e, i, o, u/), que se mantêm constantes independentemente de sua posição na palavra (BRISOLARA; SEMINO, 2014, p. 41-42).

Essa diferença no sistema vocálico é uma das dificuldades que o estudante hispanofalante pode encontrar na aprendizagem da língua portuguesa em suas variedades brasileiras, uma vez que o aprendiz se depara com um sistema que apresenta duas vogais a mais no seu inventário fonológico, como as vogais médias-baixas $/ \varepsilon / \mathrm{e} / \mathrm{J} /$.

Conforme Fonte (2010), o sistema vocálico do português arcaico herdou o sistema vocálico do latim vulgar, sendo constituído de sete fonemas vocálicos, em posição acentuada (/a, e, $\varepsilon, \mathrm{i}, \mathrm{o}$, ग, $\mathrm{u} /$ ). Observamos que o sistema vocálico do português brasileiro atual conserva o mesmo número de fonemas, em posição tônica, do sistema vocálico do português arcaico. Na posição pretônica, contudo, o sistema vocálico atual do PB mantém cinco vogais: /a, e, i, o, u/, conforme Câmara Jr. (1980, p. 43-44). Nessa posição, desaparecem as oposições entre [e] e [E] 


\section{Q Linguagens}

e entre [o] e [ว], vogais médias-altas e médias-baixas, resultando na redução do sistema vocálico. Logo, percebemos que não há distinção fonológica entre vogais médias-altas e médias-baixas em posições átonas. Notamos isso em derivações, como em $\mathrm{f}[\varepsilon]$ rro e $\mathrm{p}[\supset] \mathrm{rta}$ (posição tônica), cujas derivadas $\mathrm{f}[\mathrm{e}]$ rreiro e p[o]rteiro apresentam mudança de altura nas vogais médias. Na posição átona final, ocorre a neutralização entre [e] e [i], na série das vogais anteriores, e entre [o] e [u], na série das vogais posteriores, resultando num sistema de apenas três vogais /a, i, u/, conforme Câmara Jr. (1980, p. 43-44).

Podemos constatar que os sistemas vocálicos do português brasileiro atual já se verificavam no português arcaico. Ainda que português e espanhol mantenham algumas semelhanças, como o acento de intensidade predominantemente na penúltima sílaba, seus sistemas vocálicos se diferenciam: o espanhol apresenta em seu sistema vocálico cinco fonemas (/i, e, a, o, u/), que se mantêm tanto em posição átona como tônica, bem como em início, meio ou final de palavra.

\subsection{REPRESENTAÇÃO FONOLÓGICA DAS VOGAIS MÉDIAS-BAIXAS DO PORTUGUÊS FALADO NO BRASIL}

Conforme Matzenauer (2001), as unidades básicas da representação fonológica são traços que compõem um conjunto pequeno de categorias elementares que se combinam de vários modos para formar os sons das línguas. No modelo da fonologia autossegmental, os traços são unidades organizadas hierarquicamente, com expressão de relações de dependência e/ou dominância entre si.

Nessa perspectiva, qualquer som (consoante ou vogal) pode ser descrito pela disposição de camadas de nós de traços. No que se refere às vogais, um dos nós que compõem seu diagrama arbóreo é o nó de abertura, composto pelos traços terminais \pm abertura 1 [ab1]; \pm abertura 2 [ab2] e \pm abertura 3 [ab3], conforme Wetzels (1992). Na Figura 1, vemos a diferença de valor para o nó terminal Abertura 3, na comparação entre médias-altas e médias-baixas.

Figura 1 - Representação do sistema de abertura/altura vocálica do PB (WETZELS, 1992, p. 22).

\begin{tabular}{|c|c|c|c|c|}
\hline & $\mathrm{i} / \mathrm{u}$ & e/o & $\varepsilon / \mathrm{c}$ & $\mathrm{a}$ \\
\hline Abertura 1 & - & - & - & + \\
\hline Abertura 2 & - & + & + & + \\
\hline Abertura 3 & - & - & + & + \\
\hline
\end{tabular}




\section{W. Linguagens}

Conforme vemos na Figura 1, vogais médias-altas são especificadas como [-ab3], enquanto as médias-baixas são [+ab3]. Pela discussão desenvolvida até aqui, supomos que, em termos de representação fonológica, no espanhol, apenas /a/ esteja disponível como [+ab3]. Entendemos, contudo, que, apesar das diferenças em termos de representação fonológica, é possível o desenvolvimento de consciência de abertura de vogais do português brasileiro por estudantes hispano-falantes, considerando a sua dimensão não previsível, na distintividade, mas, principalmente, a dimensão previsível, como fruto da aplicação de regras.

Conforme vimos, há condições métricas para a manutenção das vogais médias-baixas no português brasileiro. Por isso, para a avaliação e encaminhamento de proposta de exercícios de consciência fonológica de abertura de vogais, é importante que se leve em consideração aspectos de organização do acento em português e regras que favorecem a expressão dessas vogais.

Diferentemente do estudo de Alves e Machry da Silva (2013), neste trabalho, não estamos analisando posições átonas, ainda que compreendamos a variação que se apresenta ao longo do território brasileiro. Nas cartas linguísticas referentes à distribuição das vogais médiasbaixas no Atlas Linguístico do Brasil (CARDOSO et al., 2014), vemos a realização da médiabaixa posterior na pauta postônica não final principalmente nos estados do Nordeste, com ocorrências na região Sul, no estado do Paraná (Carta F02 V3). Em relação às médias-baixas anteriores na pauta postônica não final, temos também predomínio de sua realização nos estados do Nordeste (Carta F02 V1), onde há também a concentração de realização de médias-baixas em posição átona na pauta pretônica, conforme as cartas F01 V2 e F01 V1. Ao nos abstermos de propor exercícios para as posições átonas não estamos negando a variação; estamos apenas estabelecendo um recorte para dar luz a contextos nos quais são observadas as aplicações de regras de abaixamento datílico e espondeu, sobre as quais trataremos a seguir.

\subsection{CONSTITUINTES MÉTRICOS E REGRAS DE ABAIXAMENTO}

A partir da Teoria Métrica, temos a consideração do acento como propriedade da sílaba (a qual é portadora do acento primário) e não de um segmento. Desse modo, o acento apresenta um caráter relacional, uma vez que não é considerado um traço, mas algo proeminente da 


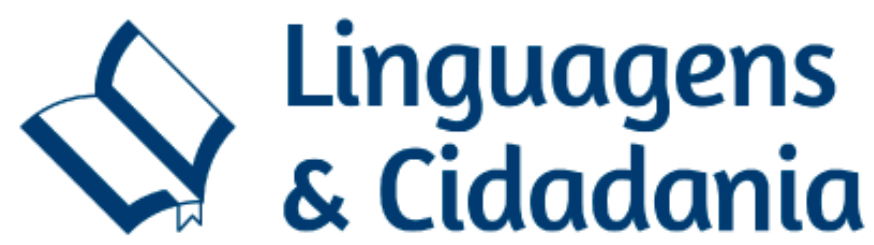

relação formada entre os elementos prosódicos, isto é, sílaba $(\sigma)$, pé $(\Sigma)$, palavra fonológica $(\omega)$ (MATZENAUER, 2001, p. 70).

A sílaba, como constituinte prosódico, constitui pés métricos, e a posição do elemento dominante (sílaba forte) é um dos parâmetros para o estabelecimento do algoritmo acentual de uma língua (COLLISCHONN, 2001, p. 70). Halle e Vergnaud (1987) propõem uma espécie de grade métrica formada por asteriscos $(*)$ e enriquecida pela formação de constituintes, cujos limites são indicados por parênteses. De acordo com Collischonn (2001, p. 126),

[...] a construção da grade métrica é realizada por um algoritmo que segue os seguintes parâmetros: a direção, o tamanho dos constituintes e a posição do cabeça. A direção de construção pode ser da direita para a esquerda ou da esquerda para a direita. Os constituintes podem ser binários, ternários ou ilimitados (neste caso, toda a sequência forma um só constituintes). A posição do cabeça nos constituintes pode ser à direita ou à esquerda. Essa posição é independente da direção de construção de constituintes.

A atribuição de acento também é regida por princípios universais que impedem que um mesmo algoritmo construa simultaneamente constituintes binários e ternários ou que construa sequência de constituintes degenerados. A noção de constituinte é pressuposto para a descrição das duas regras que veremos a seguir: de abaixamento datílico e de abaixamento espondeu. Dátilo e espondeu são pés métricos constituídos, respectivamente, na alternância, forte-fracofraco $(* .$.$) e, no padrão composto, forte-fraco (*$.), mas com última sílaba pesada. Como veremos a seguir, além da noção de dominância e de constituinte, a contagem de moras também importa na descrição da regra. Assim, considera-se que, além das vogais, também contribuem para o peso da sílaba, no português brasileiro, consoantes posvocálicas.

\subsection{PROCESSOS FONOLÓGICOS: ALÇAMENTO E ABAIXAMENTO}

As vogais do PB estão envolvidas em processos fonológicos que alteram a configuração do sistema vocálico na posição pretônica. Nessa posição, há neutralização entre as médiasbaixas / $/$ / e / $\varepsilon$ / e as médias-altas /o/ e /e/, como por exemplo, em caf/ $\varepsilon /$ - caf/e/teira, s/כ/l s/o/laço, resultando em um sistema composto de cinco vogais (/i, e, a, o, u/) (BATTISTI; VIEIRA, 2001, p. 160). Em posição pretônica, perde-se o valor positivo para o nó [ab3].

Também, na posição tônica, operam processos de mudança de traços de vogais médias. Neste caso, a neutralização apresenta-se através de dois processos: o abaixamento datílico e o 


\section{Linguagens}

abaixamento espondeu. $\mathrm{O}$ abaixamento datílico é uma neutralização prosódica condicionada que impede a presença de vogais médias-altas em sílaba tônica proparoxítona, aplicando-se em palavras derivadas e não-derivadas, como por exemplo, esquel[e]to/ esquel[ $[\varepsilon]$ tico, r[o]tulo versus $\mathrm{r}[\mathrm{o}]$ tular (BISOL, 2001, p. 172-173).

O abaixamento espondeu altera vogais médias em contexto tônico, mas em paroxítonas. De acordo com Bisol (2001, p. 175), o abaixamento “[...] ocorre em grupos de palavras que, embora constituam a sílaba final pesada [com consoante pós-vocálica], apresentam a penúltima

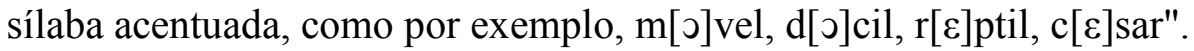

Até o momento, vimos que, no português brasileiro, há vogais médias-baixas não previsíveis e médias-baixas previsíveis determinadas pela aplicação de regras, como o abaixamento datílico e o abaixamento espondeu. Conforme apresentamos na introdução deste artigo, buscamos analisar, em manuais didáticos de PLA/PLE, oportunidades de desenvolvimento de consciência fonológica de abertura de vogais médias, considerando as suas condições prosódicas.

\section{CONSCIÊNCIA FONOLÓGICA}

De acordo com Nunes, Frota e Mousinho (2009, p. 208), a capacidade de ultrapassar a percepção auditiva e alcançar uma habilidade metafonológica é o que se compreende por uma atividade de reflexão sobre os aspectos fonológicos da língua, também conhecida por consciência fonológica. Dessa maneira, entendemos que consciência fonológica é a capacidade de identificar e de manipular deliberadamente unidades fonológicas.

$\mathrm{Na}$ consciência fonológica, identificam-se costumeiramente, pelo menos, três dimensões: a consciência silábica, a consciência dos constituintes intrassilábicos e a consciência fonêmica. Segundo Pestun (2005, p. 407), "uma das habilidades metalinguísticas é a consciência fonológica, isto é, a consciência de que a fala pode ser segmentada e que os segmentos podem ser manipulados".

Assim, é importante pensar na competência metalinguística a partir de um conjunto de habilidades que permitem ao estudante refletir e construir generalizações sobre o uso que faz da língua. A partir de Alves (2012), compreendemos consciência fonológica como sendo uma constelação de habilidades metacognitivas do falante em refletir sobre constituintes fonológicos 


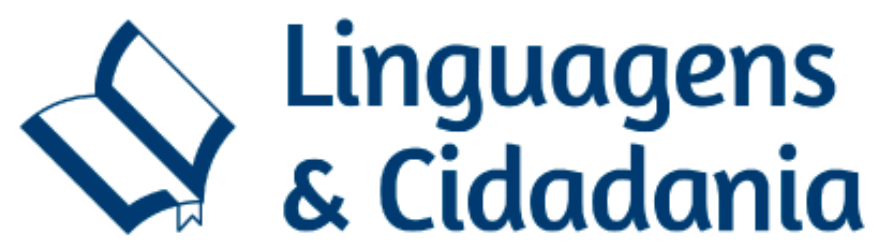

e manipulá-los. Alves (2012, p. 172), sobre consciência fonológica em L2, explica que existe uma forte relação entre os termos reflexão e manipulação, uma vez que

\begin{abstract}
Reflexão, no caso da aquisição de uma L2, implica notar o inventário de sons da língua-alvo, e, por conseguinte, as diferenças entre os sistemas de sons da L1 e da L2. Requer que o aprendiz se mostre conhecedor, implícita ou explicitamente, dos ambientes fonológicos em que tais sons podem figurar, bem como do modo como esses sons podem combinar-se entre si para formar unidades maiores, tais como sílabas e palavras. Já o termo manipulação das unidades sonoras da L2 significa operar sobre os sons da língua a ser adquirida, através de atividades como de segmentação, exclusão e transposição de sons [...]
\end{abstract}

Nesse sentido, compreendemos que consciência fonológica envolve habilidades de identificação, reflexão e manipulação de constituintes fonético-fonológicos da L2. No que concerne ao desenvolvimento da consciência fonológica em L2, Aquino (2009, p. 24) explica que é preciso que o aprendiz "reorganize seus conhecimentos de forma a criar novas categorias de sons não existentes em sua L1". Assim, ao identificar/reconhecer e refletir/assimilar os sons da nova língua/língua-alvo, o estudante estrangeiro não os distinguirá em categorias da L1, mas nas novas categorias criadas para esses sons distintivos da L2.

Diante do exposto, espera-se que os materiais didáticos de PLA/PLE escolhidos para análise apresentem atividades que transcendam a percepção auditiva, a orientação para a ortografia, a prática de pronúncia e de leitura e contribuam significativamente para o desenvolvimento do conjunto das habilidades metacognitivas dos aprendizes. Dessa forma, buscamos verificar se as habilidades metalinguísticas ora consideradas têm seu desenvolvimento oportunizado nos manuais de PLA/PLE analisados.

\title{
4 METODOLOGIA
}

Para a análise, foram selecionados os seguintes materiais didáticos: Brasil Intercultural 1 e 2 (BARBOSA; CASTRO, 2013); Brasil Intercultural 3 e 4 (BARBOSA; SCHRÄGLE, 2013); Novo Avenida Brasil 1 (LIMA et al., 2012); Diálogo Brasil - Curso Intensivo de Português para Estrangeiros (LIMA et al., 2003) e Passagens - Português do Brasil para estrangeiros (CELLI, 2002).

Os livros Brasil Intercultural 1 e 2 e Brasil Intercultural 3 e 4 são destinados a jovens e adultos hispânicos e foram escolhidos por terem sido adotados como coleção de livros-texto 


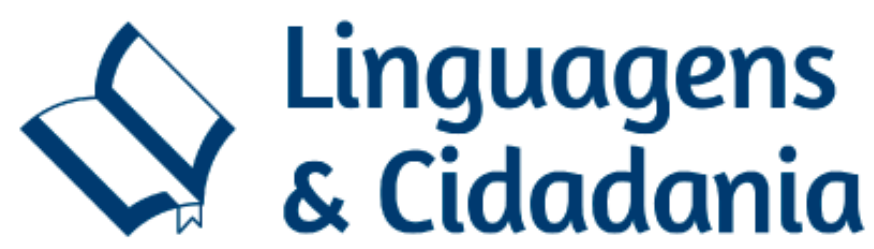

para os cursos de PLA/PLE oferecidos pelo CELE-FURG. Os demais materiais - Avenida Brasil 1, Diálogo Brasil - Curso Intensivo de Português para Estrangeiros e Passagens Português do Brasil para estrangeiros - são destinados a jovens e adultos de diferentes nacionalidades, com diversos interesses profissionais. Esses manuais didáticos foram selecionados por também estarem disponíveis no acervo do CELE.

No que tange à abordagem pedagógica dos manuais didáticos, estes apresentam propostas variadas. A Coleção Brasil Intercultural, segundo seus autores, trabalha na perspectiva intercultural, na qual se concebe a língua como lugar de interação a qual depende, e se constrói, de aspectos sociais, históricos, políticos e sociais, além de sua estrutura. O livro Novo Avenida Brasil 1: Curso Básico para Estrangeiros anuncia-se construído a partir da abordagem comunicativa, com acesso a aspectos sobre a cultura brasileira. O Diálogo Brasil Curso Intensivo de Português para Estrangeiros não menciona a abordagem a partir da qual se constitui. Segundo seus autores, no material, busca-se ir além da rotina da sala de aula, visando "a transmitir ao aluno competências linguísticas que correspondam à sua necessidade de comunicar-se corretamente em linguagem coloquial, em situações cotidianas, tanto profissionais quanto sociais". Observamos, nesse material, uma ênfase na leitura de textos escritos e gramática e, em segundo plano, a produção oral. No livro Passagens - Português do Brasil para estrangeiros, anuncia-se a prioridade no desenvolvimento das quatro habilidades comunicativas: leitura, escrita, fala e audição.

A verificação das atividades referentes às vogais médias-baixas, em cada uma das unidades dos livros, teve como base as noções teóricas de representação fonológica e de consciência fonológica. Na sequência, apresentamos a análise dos manuais didáticos selecionados.

\section{ANÁLISE E DISCUSSÃO DOS MANUAIS DE PLA/PLE}

Nesta seção, analisamos a Coleção Brasil Intercultural (BARBOSA; CASTRO; 2013; BARBOSA; SCHRÄGLE, 2013) e mais três manuais selecionados: Novo Avenida Brasil 1 (LIMA et al., 2012); Diálogo Brasil - Curso Intensivo de Português para Estrangeiros (LIMA et al., 2003) e Passagens - Português do Brasil para estrangeiros (CELLI, 2002), com a finalidade de buscar atendimento aos objetivos previamente apresentados. 


\section{Winguagens}

5.1 PASSAGENS - PORTUGUESS DO BRASIL PARA ESTRANGEIROS (CELLI, 2002)

No manual Passagens - português do Brasil para estrangeiros (CELLI, 2002), há uma seção de pronúncia, ao final do livro, no apêndice. No material, são abordadas as vogais orais $/ \mathrm{a}, \mathrm{e}, \varepsilon, \mathrm{i}, \mathrm{o}, \mathrm{\supset}, \mathrm{u} / \mathrm{e}$ as vogais nasalizadas $[\tilde{a}, \tilde{e}, \tilde{1}, \tilde{o}, \tilde{u}]$.

Notamos que não há, no livro, apresentação, para análise, das vogais médias-baixas $[\varepsilon]$ e [○]. Os exercícios propostos são orientações para a ortografia, prática de pronúncia e leitura, como por exemplo, o exercício reportado abaixo, no qual o estudante deve ler as palavras e praticar a pronúncia. Eis o exemplo de como o exercício se apresenta, com a orientação que aparece no manual, restrita à palavra "praticando".

(4) Praticando

bala - tenho- canto- caneta- vem-mala-compro-gelo-lê-tem-lição-senhor-lâmpada-vênão-irmão-tampa-mesa- põem- sim. (CELLI, 2002, p. 218)

Conforme vemos, há uma lista de palavras, talvez para leitura em voz alta, sem que o estudante seja orientado em relação ao funcionamento da atividade.

\subsection{DIÁLOGO BRASIL - CURSO INTENSIVO DE PORTUGUÊS PARA ESTRANGEIROS} (LIMA et al., 2003)

O livro Diálogo Brasil - Curso Intensivo de Português para Estrangeiros (LIMA et al., 2003) está organizado por unidades, nas quais não há abordagem a aspectos fonéticofonológicos. No final do livro, na página 249, há uma seção para fonética em que as autoras apresentam a seguinte nota explicativa: "as noções de fonética que se seguem têm por objetivo colocar o aluno diante dos sons mais importantes e mais constantes do Português do Brasil, quer sejam orais ou nasais, e auxiliá-lo na pronúncia”. As autoras trabalham com a concepção de "pronúncia padrão".

Primeiramente, são apresentadas as sete vogais orais do português brasileiro /a, $\varepsilon, \mathrm{e}, \mathrm{i}$, ว, $\mathrm{o}, \mathrm{u} / \mathrm{e}$ os quadros ortográfico e fonético das vogais. Na sequência, são propostos exercícios para ouvir, repetir e assinalar, conforme exemplo reportado em (5). 


\section{W Linguagens}

(5) Exercício reportado de Lima et al. (2003, p. 252). Ouça e assinale

\begin{tabular}{|l|l|l|}
\hline & {$[\mathrm{e}]$} & {$[\varepsilon]$} \\
\hline A festa do século & & \\
\hline Quero café & & \\
\hline Creme francês & & \\
\hline Cerveja chilena & & \\
\hline O Sudeste e o Nordeste & & \\
\hline
\end{tabular}

Apesar de termos, no exercício, a abordagem às vogais médias anteriores, não há, para além da compreensão do dado, oportunidades de manipulação. No quadro, por exemplo, há um dado de abaixamento datílico e três outras palavras com vogal média-baixa anterior, sem que haja, contudo, qualquer movimento de generalização.

\subsection{NOVO AVENIDA BRASIL 1: CURSO BÁSICO DE PORTUGUÊS PARA ESTRANGEIROS} (LIMA et al., 2012)

No manual Novo Avenida Brasil 1: Curso básico de português para estrangeiros (LIMA et al., 2012), a abordagem a aspectos fonético-fonológicos foi reservada para o apêndice, no qual são apresentadas as vogais médias-baixas por meio de exercícios de compreensão auditiva e de treino de pronúncia. Há ainda orientações referentes à relação grafema/fone, tal como: "[e] se escreve "e, ê"; [ع] se escreve "e, é". Abaixo, temos um exemplo de exercício de discriminação auditiva.

(6) Ouça o áudio e relacione. (LIMA et al., 2012, p. 103) ele, é, seu, ela, ser, até, médico, eles, elas, eu, você, português.

[e]

O manual selecionado, como vemos em (6), aborda as vogais médias-baixas do português brasileiro. Entretanto, o exercício proposto é somente de discriminação auditiva. Notamos que esse tipo de exercício, isoladamente, não possibilita a percepção de regularidades e não viabiliza a manipulação de constituintes, condições previamente apresentadas como necessárias para o desenvolvimento de consciência fonológica. 


\section{W. Linguagens}

A coleção Brasil Intercultural 1 e 2 (BARBOSA; CASTRO, 2013) e Brasil Intercultural 3 e 4 (BARBOSA; SCHRÄGLE, 2013) é composta por volumes organizados em unidades. Todas as unidades do Brasil Intercultural 1 e 2 apresentam seções de "fonética", nas quais aspectos fonético-fonológicos são abordados. No Brasil Intercultural 1 e 2, mais especificamente na página 27, a seção de fonética aborda as vogais $[\mathrm{u}],[\mathrm{o}],[\mathrm{\jmath}],[\mathrm{i}],[\mathrm{e}] \mathrm{e}[\varepsilon]$. O exercício proposto é de discriminação auditiva e de classificação. Essa atividade apresenta dois textos, cujos áudios estão disponíveis no site da editora, ambos tratando sobre questões referentes às redes sociais.

No Brasil Intercultural 3 e 4, além de serem apresentadas, em algumas unidades, seções de fonética, há também, ao final, uma página de fonética com um quadro ortográfico e fonético das vogais e consoantes do português brasileiro. O exercício proposto na página 15 é referente às vogais [o] e [0] e tem por objetivo leitura de palavras e classificação das vogais.

Apesar dos dois volumes abordarem as vogais médias-baixas do português brasileiro, percebemos que os exercícios propostos não são suficientes para oportunizar o desenvolvimento de consciência de abertura das vogais orais, pois resumem-se à discriminação auditiva e à classificação das vogais em médias-altas ou médias-baixas.

O que observamos com a análise dos materiais é que, de maneira geral, as atividades apresentadas contemplam somente habilidades de discriminação auditiva, classificação e pronúncia em exercícios de repetição. As atividades tendem a ser propostas de forma isolada, sem continuidade de exercícios sobre as vogais orais abertas do PB para que o aprendiz de fato reflita sobre o que conseguiu identificar e compreender. Logo, não lhe é dada a oportunidade de manipular as regularidades que assimilou. Tendo observado, nos manuais analisados, a carência de exercícios que possibilitem manipulação dos dados e construção de generalizações, elaboramos uma série de atividades voltadas ao desenvolvimento de consciência fonológica de vogais médias-baixas do português brasileiro em posição tônica.

6 PROPOSTAS DE ATIVIDADES DE CONSCIÊNCIA FONOLÓGICA DE ABERTURA DAS VOGAIS MÉDIAS-BAIXAS DO PORTUGUÊS BRASILEIRO 


\section{Linguagens}

As atividades de consciência fonológica de vogais médias-baixas do português brasileiro que ora propomos destinam-se a aprendizes hispano-falantes matriculados no nível A1 do curso de Português Língua Estrangeira. Como fio condutor, temos a temática “Conhecendo-nos”, a qual compõe um dos tópicos do Plano de Ensino do Curso de Português como Língua Estrangeira do nível A1 da FURG. Um dos objetivos da unidade é o desenvolvimento de competências de apresentação pessoal. A escolha da temática e do próprio tópico do Plano de Ensino encontra respaldo nas competências apresentadas/sugeridas pelo Quadro Europeu Comum de Referência para as Línguas (QECR).

O Quadro Europeu Comum de Referência para as Línguas é um documento elaborado pelo Conselho da Europa, lançado em 2001, que estabelece uma escala de seis níveis comuns de referência para a organização da aprendizagem das línguas vivas faladas na Europa, na perspectiva do plurilinguismo. Conforme consta no documento (CONSELHO DA EUROPA, 2001, p. 2008), na Escala Global, no nível A1, o aprendiz deve ser capaz de:

[...] compreender e utilizar expressões familiares e correntes assim como enunciados simples que visam satisfazer necessidades imediatas [...] apresentar-se ou apresentar alguém e colocar questões ao seu interlocutor sobre assuntos como, por exemplo, o local onde vive, as suas relações, o que lhe pertence, etc. [...] responder ao mesmo tipo de questões [...] comunicar de forma simples desde que o seu interlocutor fale clara e pausadamente e se mostre colaborante.

Diante do exposto, as atividades desenvolvidas têm por objetivos: (i) desenvolver no aluno a sensibilidade para a identificação das vogais médias-baixas do português brasileiro em posição tônica; (ii) auxiliar os estudantes estrangeiros, especialmente os alunos cuja língua materna é uma variedade do espanhol, no desenvolvimento de competências para que atinjam objetivos de ação através do uso da língua portuguesa em nível básico; (iii) promover consciência das ferramentas linguísticas necessárias para o alcance de objetivos de ação através do uso da língua; (iv) promover o desenvolvimento de consciência fonológica das vogais médias-baixas em posição tônica do português brasileiro. A seguir, disponibilizamos algumas sugestões de atividades para o desenvolvimento de consciência fonológica das vogais médiasbaixas do PB. 


\section{Q Linguagens}

No contexto das apresentações pessoais, de terceira pessoa, selecionamos, da página da Abravídeo $^{2}$, do programa Então, foi assim?, trechos de apresentação dos entrevistados do Programa 59, relativo às composições das canções Quando Eu Contar, Iaiá (Serginho Meriti/Beto Sem Braço) e Samba do Arnesto (Adoniran Barbosa). Selecionamos o trecho compreendido entre 1:44 e 3m, referente a Quando Eu Contar, Iaiá, cuja transcrição dos segundos iniciais apresentamos abaixo.

[...] nasceu em Madureira, Rio de Janeiro, no dia primeiro de outubro de 1958, mas foi criado em São João do Meriti, que lhe rendeu o nome artístico. Teve músicas gravadas por Alcione, Roberto Ribeiro, Bebeto, Beth Carvalho, Fundo de Quintal e outros renomes. Já se fez presente em programas anteriores contando a história de sua composição mais famosa "Deixa a vida me levar", gravada pelo grandioso Zeca Pagodinho, essa fábrica de sucessos, e Serginho Meriti. E a música da vez é outro grande êxito nacional: Quando eu contar, Iaiá, parceria com Beto sem braço, também gravada por Zeca Pagodinho. Você lembra? Eu tive o privilégio de entrevistar Serginho Meriti em Brasília no dia onze de agosto de 2011. Na ocasião, ele falou da trajetória, do dom de compor, e ainda me contou a interessante história de Quando eu contar, Iaiá.

Além do trecho referente a Quando eu contar, Iaiá, selecionamos, do Programa 59, o trecho compreendido entre os minutos 45:20 e 46:40, referente ao Samba do Arnesto. Separamos também recortes do Programa 51: Forró Número 1, de Antônio Barros/Cecéu (de 16:40 até 17:40), e Mama África, de Chico César (de 31:30 até 32:21). Do Programa 101 (Especial Altamiro Carrilho), destacamos dois trechos referentes a $O$ eterno jovem Bach (de 06:46 até 07:30 e de 31:30 até 32:21).

Os trechos selecionados, cujos nomes de compositores, intérpretes ou obras incluem vogais médias-baixas, serão utilizados ao longo das cinco atividades que ora propomos.

A primeira atividade tem por título Compreendendo informações de apresentação de artistas da música popular brasileira. Para o seu desenvolvimento, o professor pode pensar em exercícios de relacionar artista a (1) proveniência, (2) música gravada, (3) parceria de trabalho, (4) função (instrumentista, cantor, violonista, flautista etc.). Para a realização da atividade, serão utilizados os cinco áudios descritos previamente neste artigo. São objetivos dos exercícios possibilitar ao aluno: (i) conhecer artistas brasileiros e músicas populares brasileiras; (ii)

\footnotetext{
${ }^{2}$ A Abravídeo é uma organização não governamental que tem por objetivo criar, desenvolver e executar projetos culturais e de comunicação social. Um dos seus projetos é o programa Então, foi Assim?, cuja finalidade é, segundo Ruy Godinho, coordenador do projeto, revelar ao público as situações vivenciadas pelos autores e compositores de músicas que marcaram época no Brasil. As entrevistas realizadas com os músicos brasileiros estão disponíveis na página do programa: http://www.abravideo.org.br/
} 


\section{Ringuagens}

adquirir vocabulário referente à apresentação pessoal; (iii) identificar características e atribuições de artistas da música popular brasileira; (iv) desenvolver compreensão de vogais médias-baixas do português brasileiro.

A atividade deverá ser desenvolvida no laboratório de línguas e, antes da audição dos áudios, será necessário contextualizar o programa Então, foi assim?, conduzido por Ruy Godinho. No exercício, os alunos deverão identificar informações na apresentação dos músicos para relacionar as colunas, conforme exemplo abaixo.

(7) Leia as informações das colunas e as relacione.
(a) Serginho Miriti
( ) É um grande expoente do choro tradicional que projetou
(b) Adoniram Barbosa internacionalmente a música brasileira.
(c) Antônio Barros e Cecéu
( ) Nasceu em Madureira/Rio de Janeiro no dia $1^{\circ}$ de outubro de 1958
(d) Chico César
(e) Altamiro Carrilho
( ) Parceiros na música e na vida, são dois cantores e compositores paraibanos.
( ) João Rubinato era ator, compositor e cantor paulistano.
( ) É paraibano; nasceu em Catolé do Rocha em 1964.
( ) Teve músicas gravadas por Alcione, Roberto Ribeiro, Bebeto, Beth Carvalho, Fundo de Quintal, entre outros.
( ) Chegou a ser considerado o melhor flautista do mundo.
( ) É um grande compositor e cantor. Projetou o nome de sua cidade natal na medida em que se projetou nacionalmente com uma música que fez sucesso em 1995.
( ) Compuseram as seguintes canções: Bate coração, Por debaixo dos panos, Homem com H, Procurando tu, É proibido cochilar, entre outras.
( ) Inspirava-se em coisas simples da vida, em tipos urbanos, em acontecimentos corriqueiros para compor suas músicas. Compôs a famosa canção Saudosa Maloca, baseada numa situação de despejo.

$\mathrm{Na}$ segunda atividade, passamos à elicitação das vogais médias-baixas. Para tanto, sugerimos o uso de palavras variadas, com vogais médias-baixas não previsíveis e vogais médias-baixas resultantes da aplicação de regras, como abaixamento datílico e abaixamento espondeu. O docente deverá selecionar palavras dos áudios, as quais serão fornecidas como respostas a perguntas. Para facilitar, o vocabulário pode ser disponibilizado para os alunos em um quadro, conforme exemplo a seguir.

(8) Responda às perguntas com as informações disponibilizadas no quadro.

Chico César; O eterno Jovem Bach; Cecéu; Serginho Meriti; Zeca Pagodinho 


\section{Linguagens}

1- Quem é o intérprete de "Mama África"? Resposta: Chico César.

2- Qual música executada por Altamiro Carrilho é apresentada? Resposta: O Eterno Jovem Bach.

3- Quem compôs, com Antônio Barros, "Forró número 1"? Resposta: Cecéu.

4- Quem gravou a música “Deixa a vida me levar”? Resposta: Zeca Pagodinho.

5- Quem compôs a canção “Quando eu contar, Iaiá” em parceria com Beto sem braço? Resposta: Serginho Meriti.

Os dois primeiros exercícios são de compreensão do dado. Logo, precisamos passar à sua manipulação. É importante para o aluno compreender a diferença articulatória entre vogais médias-altas e vogais médias-baixas. Sendo assim, a terceira atividade tem foco na manipulação de características articulatórias de vogais médias-baixas.

Para mostrar a diferença de abertura dos lábios, o professor poderá utilizar como ferramenta a página fonologia.org (CRISTÓFARO-SILVA; YEHIA, 2009) ou realizar o exercício em aula por meio do uso de espelhos para que os alunos se percebam fazendo movimentos diferentes para vogais médias-altas e médias-baixas. Na sequência, o quarto exercício possibilita familiarização com símbolos fonéticos. Para tanto, serão usadas definições extraídas do dicionário Houaiss On-line, adaptadas com a inserção de transcrição fonética. No quadro abaixo (Quadro 1), temos alguns exemplos.

Quadro 1 - Algumas definições extraídas do dicionário Houaiss On-line

\begin{tabular}{|c|c|}
\hline $\begin{array}{l}\text { Época ['epokə]: Período de tempo } \\
\text { determinado tendo em conta o que nele } \\
\text { acontece, as suas características próprias ou } \\
\text { as pessoas que nele habitaram: época de } \\
\text { César; época antiga; época do mercantilismo. } \\
\text { Classe gramatical: substantivo feminino } \\
\text { Separação silábica: é-po-ca } \\
\text { Plural: épocas }\end{array}$ & $\begin{array}{l}\text { Memória [me'moriə]: Faculdade de reter } \\
\text { ideias, sensações, impressões, adquiridas } \\
\text { anteriormente. Efeito da faculdade de lembrar; } \\
\text { a própria lembrança. Recordação que a } \\
\text { posteridade guarda. } \\
\text { Classe gramatical: substantivo feminino } \\
\text { Separação silábica: me-mó-ri-a } \\
\text { Plural: memórias }\end{array}$ \\
\hline $\begin{array}{l}\text { Privilégio [privi' løzio]: Vantagem (ou } \\
\text { direito) atribuída a uma pessoa e/ou grupo de } \\
\text { pessoas em detrimento dos demais; } \\
\text { prerrogativa: os privilégios do presidente. } \\
\text { Classe gramatical: substantivo masculino } \\
\text { Separação silábica: pri-vi-lé-gi-o } \\
\text { Plural: privilégios }\end{array}$ & $\begin{array}{l}\text { Trajetória [traze'toriə]: A distância (espaço) } \\
\text { que precisa ser percorrida para se chegar a } \\
\text { outro lugar; percurso ou trajeto. } \\
\text { Classe gramatical: substantivo feminino } \\
\text { Separação silábica: tra-je-tó-ri-a } \\
\text { Plural: trajetórias }\end{array}$ \\
\hline $\begin{array}{l}\text { Maloca [ma'lokə]: Grande barraca indígena, } \\
\text { coberta de palmas secas, e que aloja várias } \\
\text { famílias; Aldeia de índios; Esconderijo. } \\
\text { Classe gramatical: substantivo feminino }\end{array}$ & \\
\hline
\end{tabular}




\section{W. Linguagens}

Flexão do verbo: $2^{\mathrm{a}}$ pessoa do singular do imperativo afirmativo, $3^{\text {a }}$ pessoa do singular do presente do indicativo.

Separação silábica: ma-lo-ca

Plural: malocas

O exercício consiste em um jogo de cartas. Em pequenos grupos, os alunos pescarão cartas e, orientados pela transcrição fonética, pronunciarão a palavra do verbete. Os colegas avaliarão se a pronúncia está adequada ou não. Estando adequada, o aluno fica com a carta. Vence quem tiver mais cartas.

Conforme vimos, no que se refere à consciência fonológica, é preciso que os estudantes possam manipular os aspectos fonético-fonológicos solicitados. Para tanto, é importante que construam categorias. Nesse caso, os alunos devem perceber que as vogais médias-baixas ocorrem (no conjunto de dados ouvidos), preferencialmente, em sílaba acentuada. Para auxiliar os estudantes na percepção da tonicidade, o docente poderá utilizar as barras da escala cuisinaire. Caso não seja possível trabalhar com esta ferramenta, o professor poderá dar orientação para desenho de barras para as sílabas, com a representação de sílabas átonas com barras menores e de sílabas tônicas com barras maiores. Entretanto, antes de começar o exercício, é importante se certificar de que os alunos conseguem separar as sílabas. Tendo identificado as sílabas tônicas, os estudantes poderão organizar as palavras, que foram oferecidas em um quadro, em uma tabela, conforme modelo abaixo.

Tabela 1 - Modelo oferecido aos estudantes

\begin{tabular}{|l|l|l|}
\hline $\begin{array}{c}\text { Proparoxítonas } \\
\text { (antepenúltima sílaba acentuada) }\end{array}$ & $\begin{array}{c}\text { Paroxítonas } \\
\text { (penúltima sílaba) }\end{array}$ & \multicolumn{1}{c|}{$\begin{array}{c}\text { Oxítonas } \\
\text { (última sílaba) }\end{array}$} \\
\hline Época & Jovem & Cecéu \\
\hline Trajetória & Maloca & Troféu \\
\hline
\end{tabular}

Construímos essas atividades com a finalidade de propor exercícios para o desenvolvimento de consciência fonológica de abertura de vogais médias em sílabas tônicas no português brasileiro. Os exercícios estão integrados aos objetivos da unidade didática construída para estudantes do nível A1 do curso de PLA/PLE do CELE-FURG e ainda serão testados em aula. Concluindo este artigo, passamos às considerações finais.

3 Ortograficamente, proparoxítonas e oxítonas terão acento gráfico; isso indicará também timbre aberto para vogais médias. 


\section{W. Linguagens}

\section{CONSIDERAÇÕES FINAIS}

Com este trabalho, buscamos verificar se há, nos manuais de PLA/PLE, abordagem às vogais médias-baixas do português brasileiro. Verificamos que, mesmo na coleção Brasil Intercultural, a qual apresenta abordagem a aspectos fonético-fonológicos no interior de suas unidades, faltam oportunidades de reflexão e manipulação dos dados oferecidos para exercício. Desse modo, verificamos uma lacuna de oferta de oportunidades de desenvolvimento de consciência fonológica de abertura de vogais médias do português brasileiro e, por isso, sugerimos atividades contextualizadas e integradas, através das quais pretendemos possibilitar a compreensão do dado, a reflexão sobre as condições para a sua ocorrência e a manipulação de suas características fonético-fonológicas.

\section{REFERÊNCIAS}

ABRAVIIDEO, Comunicação para a transformação social. Então, foi assim? Disponível em: $<$ http://www.abravideo.org.br/>. Acesso em: 2 jul. 2018.

ALLEGRO, F. R. P. Ensino de pronúncia em Português Língua Estrangeira: análise de livros didáticos. 2014. 181f. Dissertação (Doutorado em Linguística Aplicada e Estudos da Linguagem) - Pontifícia Universidade Católica de São Paulo, São Paulo, 2014.

ALMEIDA FILHO, J. C. P. Português para estrangeiros: interface com o espanhol. Campinas: Pontes Editores, 2001.

ALVES, U. K. Consciência dos aspectos fonético-fonológicos da L2. In: LAMPRECHT, R. et al. Consciência dos sons da língua: subsídios teóricos e práticos e teóricos para alfabetizadores, fonoaudiólogos e professores de língua inglesa. Porto Alegre: EdiPUCRS, 2012.

; MACHRY DA SILVA, S. M[e]nino ou m[i]nino? Bol[o] ou bol[u]? O tratamento das vogais do Português Brasileiro (LE) por manuais voltados a aprendizes argentinos.

Linguagem \& Ensino, v. 16, n. 1, 2013, p. 131-153.

ANÇÃ, M. H. A promoção e difusão da língua portuguesa - vozes de estudantes Lusófonos. Texto Livre: Linguagem e Tecnologia, v. 8, n. 2, jul./dez. 2015. Disponível em: < http://www.periodicos.letras.ufmg.br/index.php/textolivre/article/viewFile/9712/8741>. Acesso em: 12 nov. 2017. 


\section{W. Linguagens}

AQUINO, C. Uma discussão acerca da consciência fonológica em LE: o caminho percorrido por aprendizes brasileiros de inglês na aquisição da estrutura silábica. 2009. 133f. Dissertação (Mestrado em Linguística Aplicada) - Pontifícia Universidade Católica do Rio Grande do Sul, Porto Alegre, 2009.

BARBOSA, C. N.; CASTRO, G. N. Brasil intercultural: língua e cultura brasileira para estrangeiros. Ciclo básico - níveis 1 e 2. Buenos Aires: Casa do Brasil, 2013.

BARBOSA, C. N.; SCHRÄGLE, I. Brasil intercultural: língua e cultura brasileira para estrangeiros. Ciclo intermediário - níveis 3 e 4. Buenos Aires: Casa do Brasil, 2013.

BATTISTI, E.; VIEIRA, M. J. B. O sistema vocálico do português. In: BISOL, L. (Org). Introdução a Estudos de Fonologia do Português Brasileiro. Porto Alegre: EDiPUCRS, 2001, p .159-194.

BISOL, L. Introdução a estudos de fonologia do português brasileiro. 3. ed. Porto Alegre: EDiPUCRS, 2001.

BRASIL. Portaria n. 973, de 14 de novembro de 2014. Institui o Programa Idiomas sem Fronteiras e dá outras Providências. Diário Oficial da União, Brasília, DF, 17 nov. 2014. Disponível em:

<http://isf.mec.gov.br/images/pdf/novembro/Portaria_973_Idiomas_sem_Fronteiras.pdf.>. Acesso em: 25 nov. 2017.

BRISOLARA, L. B.; SEMINO, M. J. I. ¿Cómo pronunciar el español? La enseñanzade la fonética y la fonologia para brasileños: ejercicios prácticos. Campinas: Pontes Editores, 2014.

CARDOSO, S. A. M. S. et al. Atlas linguístico do Brasil. Londrina: EDUEL, 2014.

CÂMARA JR., J. M. Estrutura da Língua Portuguesa. 10.ed. Petrópolis: Vozes, 1980.

CELLI, R. Passagens: português do Brasil para estrangeiros. 1.ed. Campinas: Pontes, 2002.

COLLISCHONN, G. A Sílaba em Português. In: BISOLS, L (Org). Introdução a Estudos de Fonologia do Português Brasileiro. Porto Alegre: EDiPUCRS, 2001, p. 91-123.

CONSELHO DA EUROPA. Quadro Europeu Comum de Referência para as Línguas Aprendizagem, ensino, avaliação. Tradução Maria Joana Pimentel do Rosário e Nuno Verdial Soares. Porto: Edições Asa, 2001.

CLEMENTS, N.; HUME, E. The internal organization of speech sounds. In: GOLDSMITH J. (Ed.). Handbook of phonological theory. Oxford: Blackwell, 1995, p. 245-306. 


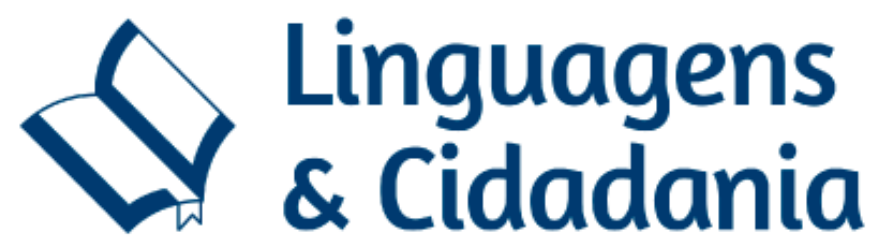

CRISTÓFARO-SILVA, T.; YEHIA, H. C. Sonoridade em Artes, Saúde e Tecnologia. Belo Horizonte: Faculdade de Letras, 2009. Disponível em: <http://fonologia.org.>. Acesso em: nov. 2017.

FONTE, J. S. Rumores da escrita, vestígios do passado: uma interpretação fonológica das vogais do português arcaico por meio da poesia medieval. São Paulo: Cultura Acadêmica, 2010. Disponível em: <http://books.scielo.org/>. Acesso em: nov. 2017.

HOUAISS. Dicionário On-line de Português. Disponível em: 〈https://www.dicio.com.br/> . Acesso em: 14 jul. 2018.

LIMA, E. et al. Diálogo Brasil: curso intensivo de português para estrangeiros. São Paulo: EPU, 2003.

Novo Avenida Brasil 1: Curso básico de português para estrangeiros: livro-texto + livro de exercícios. São Paulo: EPU, 2012.

LOPES, F. O desenvolvimento da consciência fonológica e sua importância para o processo de alfabetização. Psicologia Escolar Educacional. Campinas, v. 8, n. 2, dez. 2004.

MACHRY DA SILVA, S. A produção das vogais médias tônicas do português (12) por falantes nativos do espanhol. Organon. Porto Alegre, v. 30, n. 58, jan./jun. 2015, p. 91-108.

MATZENAUER, C. L. B. Introdução à teoria fonológica. In: BISOL, L (Org). Introdução a Estudos de Fonologia do Português Brasileiro. Porto Alegre: EDIPURS, 2001, p. 11-89.

NUNES, C.; FROTA, S.; MOUSINHO, R. Consciência fonológica e o processo de aprendizagem de leitura e escrita: implicações teóricas para o embasamento da prática fonoaudiológica. Revista CEFAC. São Paulo, v. 11, n. 2, abr.jun. 2009, p. 207-212.

OLIVEIRA, G. M. Política linguística e internacionalização: a língua portuguesa no mundo globalizado do século XXI. In: Trabalhos em Linguística Aplicada. Campinas v. 52, n. 2, dez. 2013, p. 409-433.

PESTUN, M. S. V. Consciência fonológica no início da escolarização e o desempenho ulterior em leitura e escrita: estudo correlacional. Estudos de Psicologia. Natal, v. 10, n. 3 , set./dez. 2005, p. 407-412. Disponível em:

<http://www.scielo.br/pdf/epsic/v10n3/a09v10n3>. Acesso em: 31 mai. 2018.

WETZELS, W. L. Mid Vowel Neutralization in Brazilian Portuguese. Cadernos de Estudos Linguísticos. Campinas, v. 23, jul./dez. 1992, p. 19-55. 